\title{
Analysis of the Water Level Fluctuation in Koyna-Warna Region, India
}

\author{
Ch. V. V. Eswari \\ National Geophysical \\ Research Institute (CSIR) India
}

\author{
D. V. Ramana \\ National Geophysical \\ Research Institute (CSIR) India
}

\author{
R. K. Chadha \\ National Geophysical \\ Research Institute (CSIR) India
}

\begin{abstract}
Koyna region in India is known to be the largest case of the Reservoir Triggered Seismicity (RTS) in the world with Magnitude 6.3 (M 6.3) earthquake in 1967. The region is seismically active even after forty five years with occurrences of earthquakes up to M 5.0. The porous crustal rocks of Koyna Warna region respond to changes in the prevailing stress / strain regime. These changes induce variations in the water level in bore wells before; during and after an earthquake and their study can help in understanding the earthquake genesis in the region. In this work the observed water levels in the bore wells have been analyzed and found the co-seismic water level changes in some wells. The earthquake on $14^{\text {th }}$ March 2005 with M 5.1 in Koyna - Warna region has been studied by using wavelet transformations and the results reveals the significant co-seismic changes in some of the bore wells. The Ukalu well has showed the maximum change in the water level since the epicenter is close to the well. The focal mechanism and the distance of the epicenter play important role in the variation of the water level fluctuations.
\end{abstract}

\section{INTRODUCTION}

The Koyna -Warna region is situated $225 \mathrm{~km}$ south of Mumbai and $50 \mathrm{~km}$ east of the Arabian Sea located in Maharashtra within the interior of the Indian plate. Moderate size earthquakes are occurring in this region till today even after five decays of impoundment of the Koyna reservoir. Since the origin of the earthquakes are from a small area $15 \times 30 \mathrm{~km} 2$ of the KoynaWarna region, it is ideal place to monitor the precursory phenomena to understand the earthquake mechanism. The earthquakes occur in this region show very good correlation with the annual cycle of loading and unloading of Koyna and Warna reservoir [1]. The mechanism of earthquakes in this region is identified as the reservoir triggered seismicity but it has still not been discussed satisfactorily.

There are methods to identify and study the signals and one of them are the wavelet transforms. This transforms are used in different fields of science successfully. The integral transform method in which the kernels are called wavelets is called wavelet transforms and are used to determine the temporal variations in the frequencies. This method is advantageous than the Fourier transform since it allows to determine the time dependent frequency which is not possible in Fourier transform. The wavelet transform method is useful in tracking the time evolution of the processes at different scales of the signal because of its localization properties in time and scale. Also have the advantages in analyzing the signals which contains discontinuities and sharp spikes. The wavelet transform is a tool that cuts up data or function or operators into different frequency components and then studies each component with a resolution matched to its scale.

The wavelet transform of a signal evolving in time depends on two variables (frequency and time) is used in smoothing / de- noising data based on wavelet coefficients. In non-stationary time series analysis the wavelet transform is used at many different frequencies [2]. The Morlet wavelet is first introduced and it consisting of a plane wave modulated by a Gaussian:

$$
\Psi_{0}(\eta)=\pi^{-1 / 4} e^{i \omega_{0} \eta} e^{-\eta^{2} / 2}
$$

Where $\omega 0$ is the non-dimensional frequency, here taken to be 6 to satisfy the admissibility condition [3]. This wavelet is shown in Figure 1.

$$
\Psi(\mathrm{t} / \mathrm{s})
$$
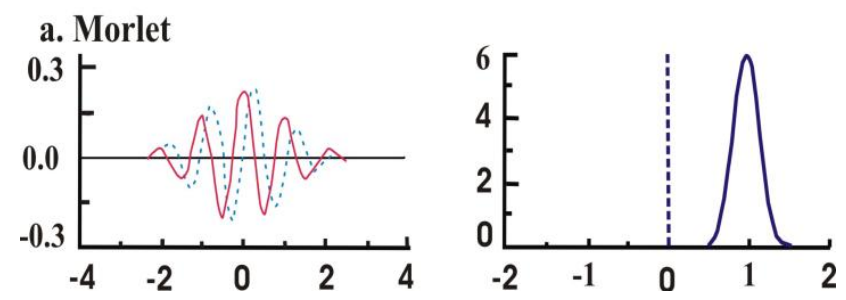

Figure 1: The Morlet Wavelet and its Transformed wavelet

Secondly, the Daubechies wavelets are a family of orthogonal wavelets defining a discrete wavelet transform and characterized by a maximal number of vanishing moments for some given support. With each wavelet type of this class, there is a scaling function (also called father wavelet) which generates an orthogonal multi resolution analysis. Daubechies wavelets are widely used in solving a broad range of problems, e.g. selfsimilarity properties of a signal or fractal problems, signal discontinuities, etc. Daubechies orthogonal wavelets D2-D20 (even index numbers only) are commonly used. The index number refers to the number $\mathrm{N}$ of coefficients. Each wavelet has a number of zero moments or vanishing moments equal to half the number of coefficients. For example, D2 (the Harr wavelet) has one vanishing moment, D4 has two, etc. A vanishing moment limits the wavelet's ability to represent polynomial behavior or information in a signal. For example, D2, with one moment, easily encodes polynomials of one coefficient, or constant signal components. D4 encodes polynomials with two coefficients, i.e. constant and linear signal components; and D6 encodes 3-polynomials, i.e. constant, linear and quadratic signal components.
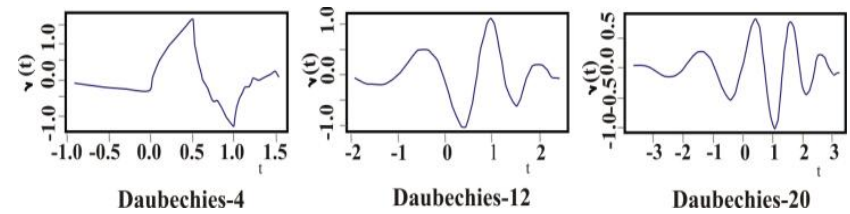

Figure 2: the wavelets are the $D_{4}, D_{12}$, and $D_{20}$ 
The first mother wavelet was given by Harr and this wavelet is given by

$$
\begin{aligned}
& \Psi(t)= \\
& \left\{\begin{array}{cc}
-1, & 0 \leq t<\frac{1}{2} \\
1, & 1 / 2 \leq t<1, \quad s_{i}=\alpha_{i}+c_{i} \\
0, & \text { otherwise. } \quad s_{i+1}=\alpha_{i}-c_{i}
\end{array}\right.
\end{aligned}
$$

Each step in the forward Haar transform calculates set of wavelet coefficients and averages. If a data set $\mathrm{s} 0, \mathrm{~s} 1, \ldots \mathrm{sN}-1$ contains $\mathrm{N}$ elements; there will be N/2 averages and N/2 coefficient values. The averages are stored in the lower half of the $\mathrm{N}$ element array and the coefficients are stored in the upper half. The averages become the input for the next step in the wavelet calculation, where for iteration $\mathrm{i}+1, \mathrm{Ni}+1=\mathrm{Ni} / 2$. The recursive iterations continue until a single average and a single coefficient are calculated. This replaces the original data set of $\mathrm{N}$ elements with an average, followed by a set of coefficients whose size is an increasing power of two (e.g., 20, 21, $22 \ldots \mathrm{N} / 2$ ).

The equations to calculate an average (ai) and a wavelet coefficient (ci) from an odd and even element in the data set are shown below:

$$
a_{i}=\frac{s_{i}+s_{i+1}}{2} \quad, \quad c_{i}=\frac{s_{i}-s_{i+1}}{2}
$$

The average is calculated by the scaling function and the coefficient is calculated by the wavelet function.

\section{STUDY AREA AND DATA ANALYSIS}

The Koyna and Warna reservoirs lie on an elevated north-south $(\mathrm{N}-\mathrm{S})$ escarpment parallel to the west coast of India. The mean elevation varies between $600 \mathrm{~m}$ on the escarpment to $100-200 \mathrm{~m}$ in the Konkan plains, towards the west coast. The escarpment is considered to be faulted [7-8]. The region is underlain by the Deccan Traps of 67.4 Ma [9] comprising several lava flow sequences. The thickness of the lavas of the Deccan Traps varies from $1.5 \mathrm{~km}$ below the escarpment to $100 \mathrm{~m}$ in the peninsular shield [10]. The Deccan Traps have low permeability but the migration of water through the faults, fractures, columnar jointing or through vesicles is quite high. A NW-SE trending lineament of $100 \mathrm{~km}$ follows the course of the Warna River and represents a fault in the Achaean basement below the Deccan Traps. The fault near the Warna reservoir is about 9m [4]. Two NNE-SSW faults are delineated from Koyna in the north to Warna in the south. The maximum number events epicenters are concentrated in an area of $15 \mathrm{~km} \times 30 \mathrm{~km}$ [4-5-6]. The main earthquakes focal mechanism is a NNE-SSW strike-slip fault [11-12]. After the main shock the consequent earthquakes in this region are showing consistent strike-slip movements on a NNE fault and normal faulting on a NW-SE fault coinciding with the Warna lineament.

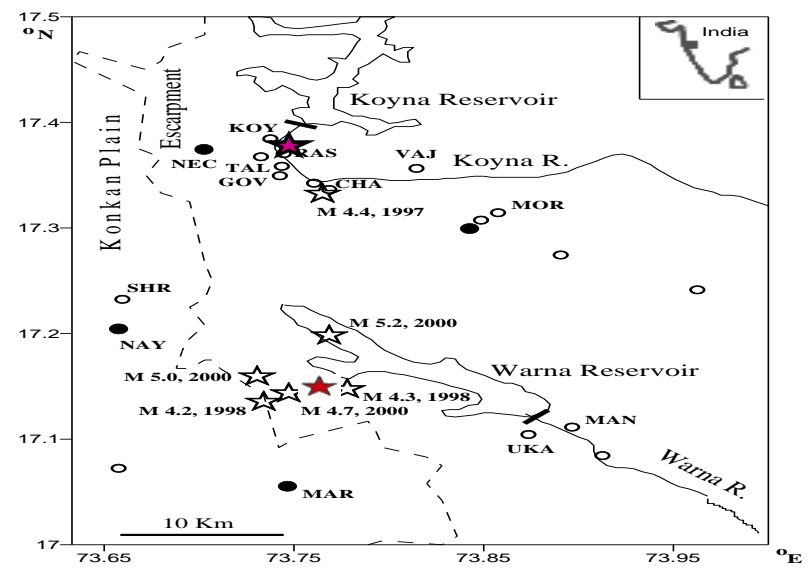

Figure 3: The Koyna - Warna region (*) stars indicated the earthquakes. Circles (open /closed) indicates the bore wells

The variation in the water levels due to an earthquake has been categorized in to three types based on seismic and transient changes. They are pre, co- and the post- seismic responses on water level variations. To understand and study the precursory phenomena in a seismically active regions, twenty one bore wells were drilled in the vicinity of the Koyna - Warna region from 1996-1998 to monitor the pore pressure changes. But presently only twelve bore wells are in operation. Figure 3 shows the location of the Koyna - Warna region in India along with the bore wells. The water level variations from 1st March to 30th March 2005 has been thoroughly studied in nine wells which the data is available are shown in Figure 4 (after tidal correction.
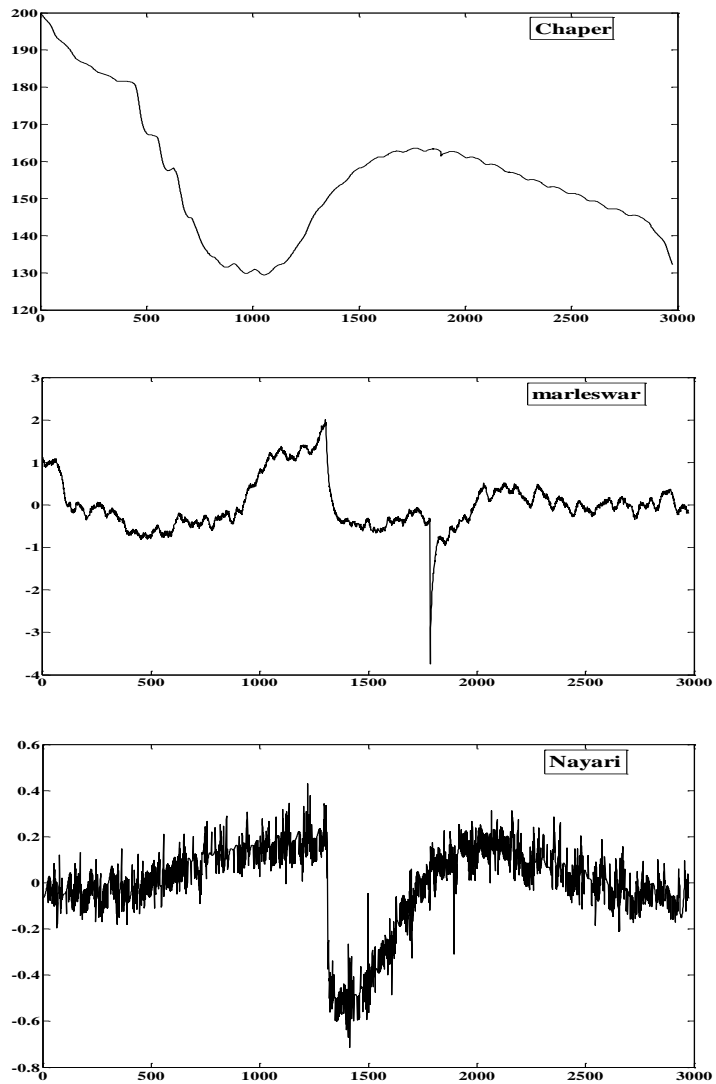

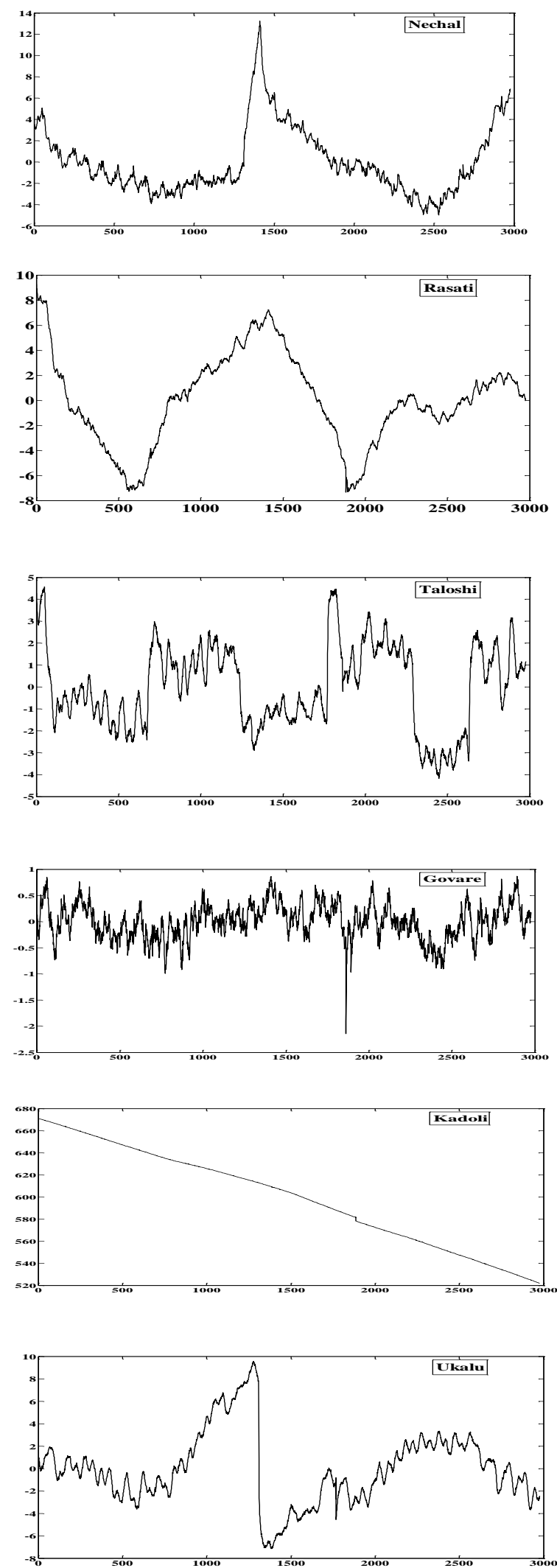

Figure 4: Water level variations of the nine bore wells from $1^{\text {st }}$ March to $30^{\text {th }}$ March 2005.

From the figure it is seen that among nine only five bore wells respond due to the $14^{\text {th }}$ March 2005 earthquake. The Marleswar, Nayeri, Nechal and Ukalu bore wells show the co seismic effect of water level variation at the time of event. From the original time series it is also observed that Nechal shows sudden rise whereas the other three wells show sudden drop in the water level at the time of the event. Taloshi also show some signatures but not as clear as other four bore wells. Since the magnitude of the earthquake is more than M 5.1 and the focal mechanism is normal fault the co seismic changes observed in the wells are sudden drop/rise. . This type of effects are previously observed for September 2000 earthquake in Koyna - Warna region.

\section{RESULTS AND DISCUSSIONS}

The wavelet $\left(\mathrm{D}_{2}\right)$ transform is applied for all the bore well water level time series and the first and second coefficients are shown in figure 5. From the figure it is seen that the first coefficient shows very clear peak at the time of $14^{\text {th }}$ Mar 2005 M5.1 earthquake peaks for Ukalu and Marleswar wells.
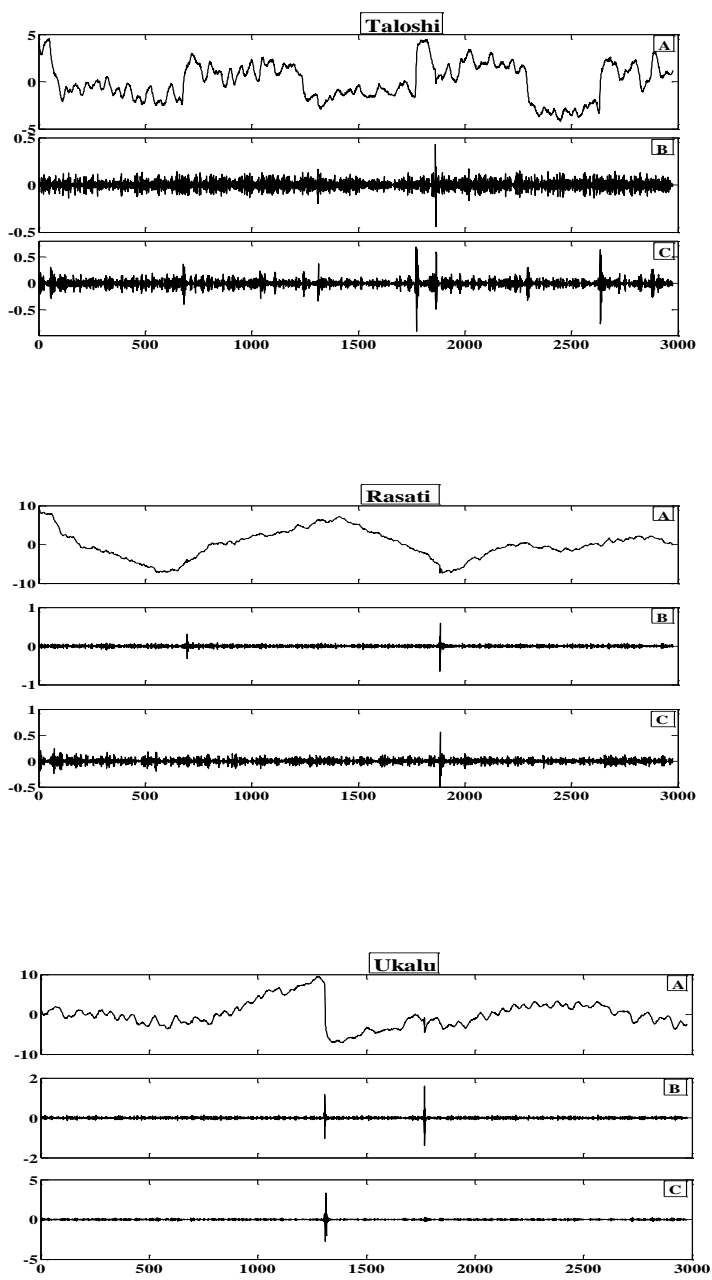


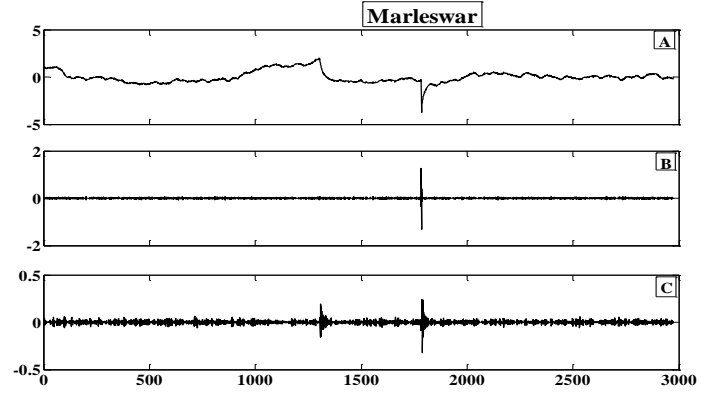

Figure 5: (A) The original water level data from $1^{\text {st }}$ March to $31^{\text {st }}$ march 2005 for Taloshi, Rasati, Ukalu and Marleswar bore wells (after removing the tidal effects) (B) first coefficient $(C)$ the second coefficient

These peaks in the coefficients correlated with the sudden changes in the original time series and also correlated with the co-seismic effect of the event. The second coefficient shows some small signatures at the time of event in the Taloshi well. This gives the importance of the method in identifying the coseismic effect even though it is not significantly shown in the original signal.

The first coefficient also shows a significant peak at around 24th March 2005 in most of the time series data. In the second coefficient both the anomalies are seen most of the time. These two peaks can be correlated with co seismic effect of 14th March as the first anomaly (Peak) and the other one also is the coseismic effect of the 24th March event with less magnitude. Sometimes this can also be explained as the delay effect of the earthquake as the second peak and this can be correlated with recovery period/ time taken to come to the original stress field. The first and second level D1 and D2 shows the discontinuities more clearly because rupture contains the high frequency part. In identifying the discontinuities or sudden changes in the water level data, Daubechies wavelet would be a more useful wavelet and the discontinuity is localized very precisely only in a small domain using this wavelet.

To validate the method also studied the different time series with different events of lesser magnitude. The water level data for the month of August 2005 has been considered since there is an event occurred on 30th Aug. 2005 with M 3.5. The variations in the water levels at the time of event are not clear to study the coseismic effect in long data set of one month. To see the signatures more clearly the data set is reduced to five days from 27 th to 31st of Aug 2005. The wavelet transformation has been applied to the five days data sets. The original time series along with the approximate and detailed coefficients are shown in figure 6 . From the figure it is clearly seen the peaks in the detailed coefficients at the time of event (30th Aug 2005) in some of the bore well water levels like Ukalu and Govare wells. This shows the importance of the wavelet transform in identifying the co-seismic effect of the earthquakes in water levels up to some magnitudes.
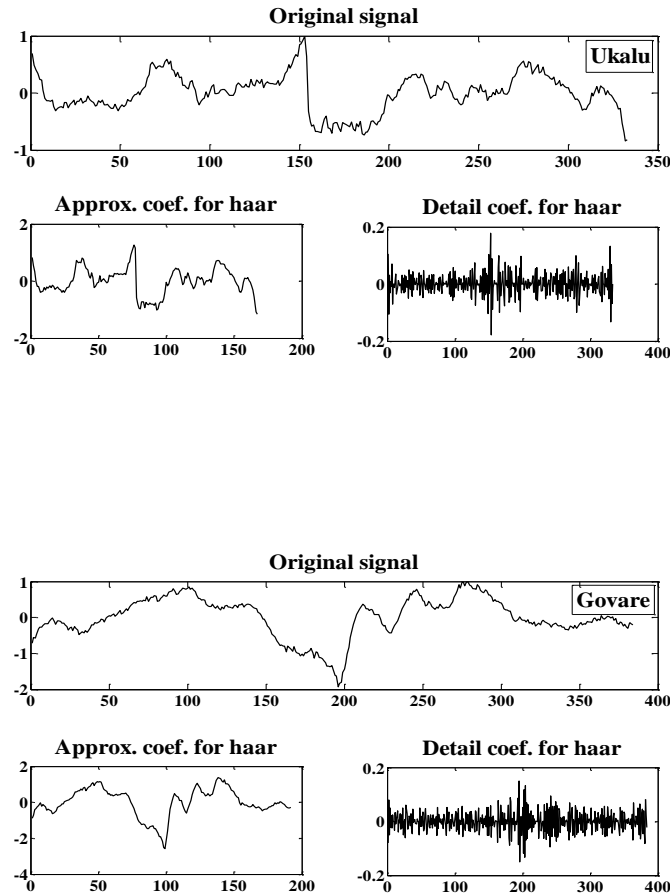

Figure 6: The original water level data (after removing the tidal effects) from 27th Aug to 31st Aug 2005 with its approximate and detailed coefficients for (a) Ukalu and (b) Govare bore wells.

Another data set of the Ukalu well in February 1998 is also studied for clear understanding of co-seismic effects using the wavelet transforms. The results are shown in fig. 7 .
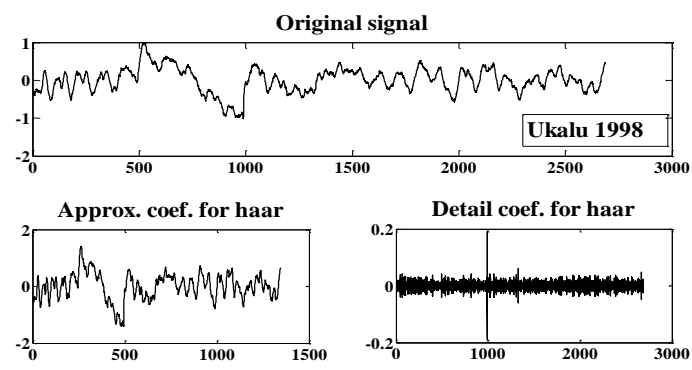

Figure 7: The Ukalu bore well water level data for 1998 and its coefficients

The amplitude of the variation in the water levels at different wells has been determined at the time of event and tabulated in Table 1. From the Table 1 it is seen that the maximum variation in the water levels at Ukalu bore because this well is situated close to the epicenter of the event. And it can also conclude that the water level drop (- ve) when the bore well situated in the extension forces and the water level rises $(+v e)$ if it is in the compression forces. 
Table 1. Water level variations in different wells due to 14th March, 2005 M5.1 event

\begin{tabular}{lc}
\hline Name of the well & Variation in the water level (cm) \\
\hline & \\
Ukalu (UKA) & -14 \\
Nechal (NEC) & +9 \\
Taloshi (TAL) & +3
\end{tabular}

\section{CONCLUSIONS}

The bore well water level variations from 1st March to 30th March 2005 has been thoroughly studied in twelve wells. The earthquake of M 5.1 has occurred on 14th March 2005 and the time series has been chosen for one month March 2005 data. Since the magnitude of the earthquake is more than 5.1 and the focal mechanism is normal fault, the co seismic changes observed in most of the observed wells are sudden drop (except Nechal). This type of observations is shown in Koyna - Warna region for September 2000 earthquake also. The coefficients of the discontinuous wavelet transform of the time series by applying the daubechielet transform shows the significant peaks and it can be correlated with the occurrence of an earthquake. The water level variations in some of the bore wells show 6 to 8 days prior to the original earthquake (14th March 2005). This can be seen in the decomposition coefficients of the daubechielet type of the wavelet transform. No exact correlation is observed between the amplitude of the water level variation and the distance but the amplitude is more if the epicenter is close to the bore well. The focal mechanism and the distance of the epicenter play important role in the variation of the water level fluctuations.

\section{DATA AND RESOURCES}

All the analysis was performed using Matlab 7.6.

\section{ACKNOWLEDGEMENTS}

The authors are grateful to the Director, National Geophysical Research Institute for his kind permission to publish this work.

\section{REFERENCES}

[1] Chadha, R. K., and A. P. Pandey (2003). Search for earthquake precursors in well water levels in a localized seismically active area of Reservoir Triggered Earthquakes in India, Geophysical Research Letters, 30, 69:1-4.

[2] Daubechies, I. (1990). The wavelet transform time frequency localization and signal analysis, IEEE Trans. Inf. Theory, 36, 961-1005.

[3] Farge, M. (1992). Wavelet transforms and their applications to turbulence, Ann. Rev. Fluid Mech, 24, 395-457.

[4] Rajurkar, S.T., V. D. Bhate, S. B. Sharma (1990). Lineament fabric of Madhya Pradesh and Maharashtra and its tectonic significance, Precambrian of Central India. Geological Survey of India Special Publication, 28, 241-259.

[5] Chadha, R. K., H. K. Gupta, H. J. Kue mpel, P. Mandal, A. Nageswara Rao, I. Radhakrishna, B.K. Rastogi, I.P. Raju, C. S. P. Sarma, C. Satyamurthy, H. V. Satyanarayana (1997). Delineation of active faults, nucleation process and pore pressure measurements at Koyna (India), Pure Appl. Geophys, 150, 551-562.

[6] Talwani, P. (1997). Seismotectonics of the Koyna-Warna area, India, Pure Appl. Geophy, 150, 511-550.

[7] Pascoe, E.H. (1964). A Manual of the Geology of India and Burma, vol. 3. Government of India Press, Calcutta.

[8] Valdiya, K.S. (1984). Aspects of Tectonics: Focus on SouthCentral Asia, McGraw-Hills, New Delhi.

[9] Duncan, R. A., D. G. Pyle (1988). Rapid eruption of Deccan flood basalts at the retaceous/Tertiary boundary, Nature, $333,841-843$.

[10] Kailasam, L.N., A.G. B Reddy, M. V. Joga Rao, Y.K. Satyamurthy, B. P. R. Murthy (1976). Deep electrical resistivity soundings in the Deccan Trap region, Curr. Sci. $45,9-13$.

[11] Langston, C.A., M. Franco-Spera (1985). Modeling of Koyna India, aftershock of 12th December 1967, Bull. Seismol. Soc. Am, 75, 651-660.

[12] Dziewonski, A. M., G. Ekstrom, J. E. Franzen, J. H. Woodhouse (1988). Global seismicity of 1980 Centroid moment tensor solutions for 515 earthquakes, Phys. Earth. Planet. Int, 50, 127-15. 